\title{
Uma leitura dos fluxos migratórios através da Teoria dos Grafos: contribuições ao estudo da formação da macrometrópole paulista
}

Luiz Antonio Chaves de Farias*

Bladimir Carabali Hinestroza**

\section{Introdução}

O presente trabalho tem como objetivo avaliar as tendências e características dos fluxos migratórios, segundo a perspectiva da hierarquia urbana, na chamada "Macrometrópole Paulista" no período 2000 e 2010. Entende-se que o estudo do quadro mais atual de evolução do referido fenômeno pode contribuir significativamente para a avaliação do processo de interação e complementaridade sócio-espacial existente dentro e entre as unidades urbanas que formam esse "arranjo urbano-regional" (utilizando-se dos termos de Moura [2009]) ainda em consolidação.

A "Macrometrópole Paulista", assim definida pela EMPLASA (2012), envolve 168 municípios distribuídos entre as quatro tradicionais Regiões Metropolitanas oficiais do Estado de São Paulo, além de municípios situados nas regiões de influencia de Piracicaba, Sorocaba, Jundiaí, São Roque e Bragança Paulista ${ }^{a}$ (Mapa 1).

Ocupando, segundo dados de Cunha et al. (2013), 20\% do território do estado de São Paulo, possui 30 milhões de habitantes, representativos de cerca de $73 \%$ da população do estado. Além disso, em termos econômicos, produz $83 \%$ da riqueza do estado e $28 \%$ do total produzido no país.

Se no nível de agregação integral de seu territorial pode-se traçar um panorama relativamente preciso de sua magnitude e representatividade a nível macrorregional e nacional, conforme brevemente esboçado no parágrafo anterior. Quando se olha para dentro da região, algumas lacunas empíricas e, principalmente, teóricas começam a surgir. É, pois, no sentido de trazer contribuições ao preenchimento dessas lacunas que se esboça o quadro de análise de caráter exploratório-descritivo seguido pelo trabalho.

Em primeira mão, situa-se em qual debate dentro dos Estudos Urbanos está inserida a "Macrometrópole Paulista". Em seguida, explica-se sob uma perspectiva

\footnotetext{
*Doutorado em Demografia (IFCH/NEPO/UNICAMP)

**Doutorado em Demografia (IFCH/NEPO/UNICAMP)

a Ressalta-se que recentemente a então aglomeração urbana de Sorocaba foi também alçada à categoria de Região Metropolitana.
} 
metodológica o que é a "Teoria dos Grafos", suas possíveis contribuições ao estudo dos fluxos migratórios da área de estudo e como será aplicada no trabalho. Por fim, procedese a análise dos resultados obtidos.

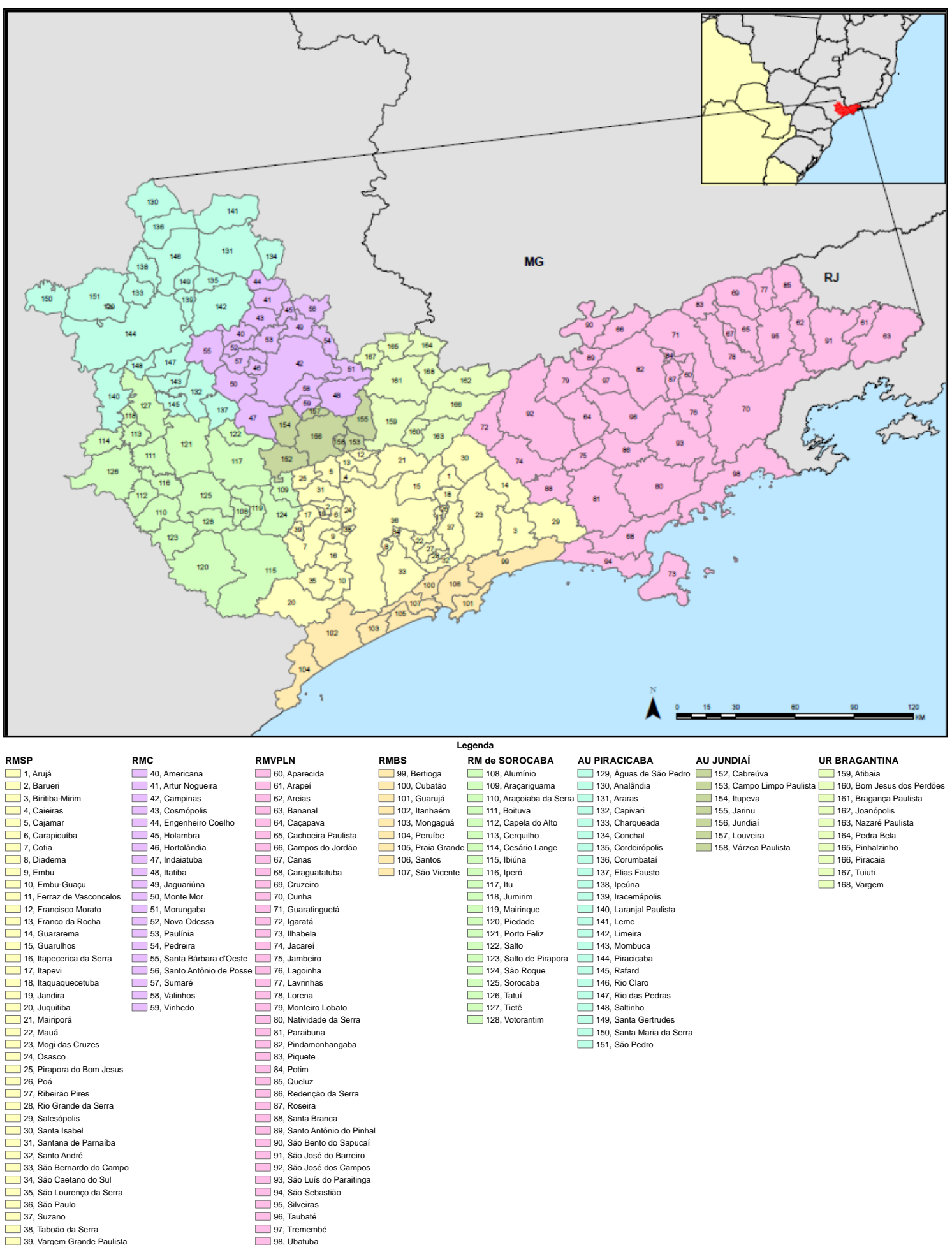

Mapa 1 - Localização da Área de Estudo (“Macrometrópole Paulista” Segundo Unidades Urbanas em 2015)

Fonte: EMPLASA. Organização: Autores. 


\section{Entre a Rede Urbana e o Espaço Intra-urbano}

A perspectiva de análise delineada na introdução aufere grande importância no período atual, já que, segundo Van Oort et al. (2009), face aos novos avanços nas tecnologias de comunicação e transporte, é esperado que significativas ligações funcionais que eram tradicionalmente vinculadas ao espaço urbano ocorram em escalas geográficas cada vez maiores. Neste ponto de vista, as áreas metropolitanas perderiam importância como sistemas urbanos funcionais diários independentes (daily urban systems), podendo, ao invés disso, serem percebidas como fazendo parte de uma rede urbana.

Na realidade urbana brasileira, tal discussão foi levantada por Corrêa (ca. 2011) que propôs a introdução da escala intermediária da megalópole e dos eixos urbanizados, na qual, segundo referido autor, a rede urbana metamorfoseia-se em espaço intraurbano e este assumiria nitidamente a forma de segmento da rede urbana. Goei et al. (2009), ao analisar o desenvolvimento do sistema de cidades do sudeste do Reino Unido, ratifica tal proposta de análise quando considera que ultimamente tem ocorrido uma maior complexidade das ligações funcionais na escala interurbana ao nível regional. Conclui salientando a importância do cruzamento das escalas intraurbana (local) e interurbana (regional).

Dentro da operacionalização escalar seguida pelo presente estudo, de acordo com Cunha (2011), as modalidades migratórias ocorridas no interior da Macrometrópole Paulista passaram a ganhar notoriedade nas últimas décadas na medida em que os grandes fluxos migratórios inter-regionais se arrefeceram a partir do final dos anos 80. No entanto, o caso específico paulista se mostra relativamente inovador, tendo em vista que se a mobilidade residencial intra-metropolitana não é uma novidade, conforme ressaltado pelo referido autor, os fluxos migratórios “intramacrometropolitanos”, o são.

$\mathrm{O}$ fato de tais movimentos resguardarem aspectos vinculados tanto ao espaço urbano quanto à rede urbana impõe igualmente a mescla de perspectivas teóricas e analíticas de apreensão do fenômeno para as duas escalas. Segundo Correa (2011), os fenômenos, relações sociais e práticas espaciais mudam ao se alterar a escala espacial da ação humana, assim como, modifica-se a sua representação cartográfica. A base teórica, que permite explicar ou compreender fenômenos, relações e práticas, é alterada ao se mudar a escala espacial. Isto é ilustrado, de acordo com exemplo trazido pelo autor 
supracitado, com as formulações de Todaro, de um lado, e Guademar, de outro, na explicação das migrações em escala nacional ou internacional. Ambas as teorias tornam-se pouco úteis quando se considera as mudanças de domicílio no espaço intraurbano (mobilidade residencial intra-urbana).

\section{A Teoria dos Grafos e sua Leitura da Espacialidade dos Fluxos Migratórios}

Em vista de levantar contribuições a debate sucintamente apresentado acima, lançou-se mão da aplicação da Teoria dos Grafos na análise dos fluxos migratórios correntes na "Macrometrópole Paulista", captados a partir do quesito de data fixa dos dois últimos levantamentos censitários, segundo a unidade de análise dos municípios. Os procedimentos técnicos seguidos no presente trabalho estão respaldados nos perspectivas teórico-operacionais dos estudos de redes geográficas propiciadas pela Teoria dos Grafos.

De acordo com Harary (1969), a Teoria dos Grafos teve sua origem no século XVIII, quando o matemático alemão Euler, ao tentar resolver o problema das sete pontes da cidade de Kognisberg, gerou os conceitos básicos dos grafos. Entretanto sua aplicação ao estudo de redes geográficas somente se daria em 1960, em trabalho pioneiro de Garrison (1960), ao estudar o sistema de auto-estradas americano. No Brasil a teoria dos grafos ainda ressente-se de maiores aplicações, destacando-se seu uso nos estudos de Teixeira (1975), Ramos (1998), Farias (2014) e Correa (2006).

Segundo Teixeira (1975), a Teoria dos Grafos constitui a parte da Topologia Geral que estuda as relações que existem entre os elementos de um sistema, independentemente das propriedades métricas deste, desprezando conceitos, tais como distância, forma e dimensão. Assim, apenas se leva em consideração os vértices e as ligações entre os mesmos. Neste sentido, um grafo se conformaria enquanto um modelo.

Os grafos podem ser planares e não planares. Os primeiros são aqueles em que as interações ou vias somente se cruzam por intermédio de nós, implicando na necessária existência de mediações para que os fluxos possam se verificar. Os grafos não planares, por sua vez, são definidos como aqueles nos quais as interações ou vias se cruzam sem a mediação de nós. Estes últimos grafos mostram uma maior complexidade funcional da rede geográfica em questão.

Como nos aponta Harary (1969) há três tipos de grafos: grafo em árvore, grafo em barreira e grafo em circuito. 
O grafo em árvore (branching network) não contém circuitos, existindo apenas um caminho possível entre um par de vértices (grau de recepção igual a um); estes grafos são úteis na análise das relações do tipo árvore genealógica, na análise de bacias fluviais, etc. O grafo em barreira (barrier network) é formado por um conjunto de ligações que bloqueiam ou detêm os fluxos; é utilizado na geografia política e na estrutura fundiária. O grafo em circuito (circuit network) apresenta uma estrutura constituída de curvas fechadas ou circuitos, permitindo opção no caminho a ser seguido; é utilizado na análise de sistemas de transportes (TEIXEIRA, 1975:25)

Conforme nos indica Correa (1999), uma rede ao ser transformada em seu correspondente grafo pode ser avaliada em seu conjunto a partir de medidas estruturais que possibilitam mensurar o seu grau de conectividade. Na visão de Teixeira (1975), os índices estruturais, utilizando vértices, ligações e subgrafos, permitem medir o grau de coesão de uma rede, através das características gerais da mesma. Esses índices possibilitam a comparação entre redes distintas bem como entre os diversos estágios de desenvolvimento de uma mesma rede, aplicação do presente estudo. Entre estes índices citam-se: o índice beta, que expressa a relação entre número ligações (e) e o número de nós (v) - $\beta=\mathrm{e} / \mathrm{v}$; o índice gama, que mensura a importância relativa das ligações existentes (e) em comparação ao número máximo possível de ligações $-\gamma=(\mathrm{e} / 3$ (v2))x 100; e, o índice alfa que se refere a importância relativa dos circuitos existentes em uma rede geográfica em relação ao número máximo possível de circuitos - para grafos planares, $\alpha=((\mathrm{e}-\mathrm{v}+1) /(2 \mathrm{v}-5)) \times 100$, e para não planares, $\alpha=((\mathrm{e}-\mathrm{v}+1) /(\mathrm{v}(\mathrm{v}-1)-(\mathrm{v}-$ 1)))x100. Para maiores detalhes da construção dessas fórmulas e do cálculo de outras medidas estruturais de grafos, ver Correa (1999).

Por sua vez, Nystuen e Dacey (1961) aplicaram a teoria dos grafos aos Estudos Urbanos, utilizando o fluxo de ligações telefônicas no estado de Washington nos Estados Unidos. Utilizando notação matricial (matriz de intensidade), identificaram alguns conceitos da teoria dos grafos aplicáveis aos Estudos Urbanos, especialmente às redes urbanas: 1 - uma cidade é independente de seu fluxo máximo se se dirige para uma cidade menor; 2 - transitividade - se a cidade A é subordinada a cidade B e B é subordinada à cidade $\mathrm{C}$, então $\mathrm{A}$ é subordinada a $\mathrm{C} ; 3$ - uma cidade não é subordinada a nenhuma de suas subordinadas. ${ }^{\text {b }}$

Para a aplicação da Teoria dos Grafos ao presente estudo, como ponto de partida, foram construídas duas matrizes migratórias, representativas de cada período

\footnotetext{
b Para fins do presente trabalho se mensurou o tamanho das cidades a partir da magnitude total de imigração dos fluxos provenientes da "Macrometrópole Paulista". Além disso, admitiu-se como representativos para a aplicação da "Teoria dos Grafos" apenas aqueles municípios com imigração acima de 1000 pessoas.
} 
considerado. Por mostrarem relacionamentos entre lugares, são, portanto, classificadas como matrizes de interações espaciais.

A partir das mesmas, confeccionou-se quadros e mapa de fluxos, representativos da magnitude dos fluxos migratórios mais representativos, como também das relações de independência e subordinação entre os municípios que conformam a área de estudo. Acredita-se que partir desses produtos, poder-se-á identificar a interação e complementariedade sócio-espacial existente entre os municípios e metrópoles que compõem a macrometropóle paulista, assim como em que medida as diferentes modalidades migratórias abrangidas são representativas das mesmas.

\section{Os Padrões Espaciais dos Fluxos Migratórios na Macrometrópole Paulista em 2000 e 2010}

Atentando-se aos resultados alcançados pelo trabalho, analisam-se os fluxos migratórios de primeira ordem (maior fluxo dentre aqueles originários em um determinado município) dos quinquênios 1995-2000 e 2005-2010 (Tabelas 1 e 2, Quadros 1 e 2, e, Mapas 2 e 3).

Em primeira linha, calculou-se o índice gama (descrito na sessão anterior). Tal medida aponta um nível de articulação de $19,79 \%$ e 20,31\% da rede urbana analisada através de seus movimentos migratórios para os dois períodos considerados. Tal valor se mostra relativamente condizente com a natureza de tal tipo de fluxo que sofre uma grande fricção causada pela distância, se comparado a outros já calculados para o mesmo contexto espacial, como os pulsos telefônicos mensurados por Ramos (1998), que chegou ao valor de $99 \%$ para a rede urbana paulista.

Ainda na análise dos níveis de integração regional (tabelas 1 e 2), percebe-se que no primeiro qüinqüênio $93,9 \%$ dos fluxos ocorreram dentro das unidades regionais. Tal cenário é levemente alterado em 2005-2010, já que 91,5\% dos fluxos ocorreram no interior das mesmas, evidenciando o caráter predominante de "mobilidade residencial" das modalidades migratórias em questão. Por outro lado, nas unidades regionais de menor consolidação e hierarquia urbana regional, como a UR Bragantina e a AU de Piracicaba, os movimentos migratórios intra-regionais têm menor peso no total, na ordem de $13 \%$ e $46 \%$, respectivamente no último ano. 
Além disso, a partir dos mapas 2 e 3, foi possível medir a distância média dos fluxos ${ }^{\mathrm{c}}$, que no primeiro qüinqüênio era de cerca de $30 \mathrm{~km}$ e no último era em torno de $34 \mathrm{~km}$. Aqueles com destino a São Paulo foram em média de $68 \mathrm{~km}$ e $78 \mathrm{~km}$, ressaltando-se uma maior heterogeneidade das modalidades migratórias com este destino.

Tabela 1 - Origem e Destino dos Fluxos Pendulares de $1^{\text {a }}$ Ordem na Macrometrópole Paulista Segundo Unidades Regionais 1995-2000

\begin{tabular}{|c|c|c|c|c|c|c|c|c|c|}
\hline \multirow{2}{*}{\multicolumn{2}{|c|}{ Unidades Regionais }} & \multicolumn{8}{|c|}{ Destino } \\
\hline & & RMVPLN & RMBS & UR Bragantina & AU Jundiaí & RMC & AU Piracicaba & RM Sorocaba & RMSP \\
\hline \multirow{8}{*}{ Origem } & RMVPLN & 12546 & 0 & 0 & 0 & 0 & 0 & 0 & 737 \\
\hline & RMBS & 0 & 23061 & 0 & 0 & 0 & 0 & 0 & 1237 \\
\hline & UR Bragantina & 0 & 0 & 756 & 0 & 0 & 0 & 0 & 1468 \\
\hline & AU Jundiaí & 0 & 0 & 0 & 3594 & 0 & 0 & 0 & 0 \\
\hline & RMC & 0 & 0 & 0 & 390 & 10356 & 0 & 0 & 0 \\
\hline & AU Piracicaba & 0 & 0 & 0 & 0 & 458 & 3266 & 736 & 1706 \\
\hline & RM Sorocaba & 0 & 0 & 0 & 0 & 0 & 0 & 7448 & 0 \\
\hline & RMSP & 343 & 0 & 0 & 0 & 0 & 0 & 0 & 48008 \\
\hline
\end{tabular}

Fonte: IBGE. Dados Brutos do Censo Demográfico 2000.

Organização: Autores

Tabela 2 - Origem e Destino dos Fluxos Pendulares de $1^{\text {a }}$ Ordem na Macrometrópole Paulista Segundo Unidades Regionais 2005-2010

\begin{tabular}{|c|c|c|c|c|c|c|c|c|c|}
\hline \multirow{2}{*}{\multicolumn{2}{|c|}{ Unidades Regionais }} & \multicolumn{8}{|c|}{ Destino } \\
\hline & & RMVPLN & RMBS & UR Bragantina & AU Jundiaí & RMC & AU Piracicaba & RM Sorocaba & RMSP \\
\hline \multirow{8}{*}{ Origem } & RMVPLN & 14896 & 0 & 0 & 0 & 0 & 0 & 0 & 405 \\
\hline & RMBS & 0 & 9521 & 0 & 0 & 0 & 0 & 0 & 1235 \\
\hline & UR Bragantina & 0 & 0 & 257 & 0 & 94 & 0 & 0 & 1539 \\
\hline & AU Jundiaí & 0 & 0 & 0 & 2100 & 239 & 0 & 0 & 218 \\
\hline & RMC & 0 & 0 & 0 & 0 & 6602 & 0 & 0 & 213 \\
\hline & AU Piracicaba & 0 & 0 & 0 & 0 & 831 & 3024 & 309 & 2271 \\
\hline & RM Sorocaba & 0 & 0 & 0 & 0 & 0 & 49 & 7115 & 1452 \\
\hline & RMSP & 298 & 0 & 0 & 0 & 0 & 0 & 0 & 55093 \\
\hline
\end{tabular}

Fonte: IBGE. Dados Brutos do Censo Demográfico 2010.

Organização: Autores

No que toca às relações de subordinação entre os centros urbanos da "Macrometrópole Paulista" (quadros 1 e 2), chama atenção a força dos centros urbanos independentes do interior, responsáveis por subordinar direta ou indiretamente 104 e 95

${ }^{\mathrm{c}}$ Utilizou-se o centróide do polígono representativos dos municípios nos mapas, enquanto proxy espacial das sedes municípios, áreas estas de onde se pressupõe partam a maior parte dos fluxos migratórios. 
municipalidades, concorrendo, portanto, com a metrópole paulistana, que sozinha ainda subordinava 37 e 49 municípios em 1995-2000 e 2005-2010, respectivamente. Ademais, verificou-se uma tendência de verticalização da hierarquia urbana, considerando-se que São Paulo passa a subordinar centros urbanos até o nível D no qüinquiênio mais recente, ante até o nível $\mathrm{C}$ do anterior. Tal aspecto relativiza a tese de interiorização do crescimento urbano corrente nas três últimas décadas, tendo em vista que nos anos 2000 se auferiu um leve aumento da primazia da cidade de São Paulo enquanto destino dos fluxos migratórios de primeira ordem.

Da mesma forma, conforme pode ser observado nos quadros abaixo, e principalmente, nos mapas 2 e 3, observa-se que para as cinco regiões metropolitanas consideradas (São Paulo, Campinas, Sorocaba, Baixada Santista, e Vale do Paraíba e Litoral Norte), em sua grande parte para os dois períodos considerados, a hierarquia urbana se deu no sentido núcleo-periferia, reforçando-se aí o argumento de que o padrão de estruturação urbana, centro-periferia, ainda é forte em tais contextos metropolitanos. Estes últimos resultados e aqueles discutidos no parágrafo anterior dialogam em linhas gerais com as discussões de DAVIDOVICH (2004), que ao discutir a "volta da metrópole" no Brasil, justamente advoga a manutenção do modelo centro-periferia enquanto padrão de estruturação metropolitana corrente, assim como, a retomada do crescimento das grandes aglomerações urbano-regionais brasileiras nas últimas décadas do século XX.

No entanto, a Baixada Santista apresenta um padrão relativamente distinto das outras aglomerações urbanas consideradas, já que seu núcleo não é um centro urbano independente, sendo subordinado de um município "periférico" de sua estrutura urbana, Praia Grande, que é reconhecidamente um vetor de expansão da região (JAKOB, 2003). Ao lado disso, percebe-se que os municípios de Peruíbe, Itanhaém, Mongaguá e Bertioga, estão subordinados à metrópole paulistana. O panorama encontrado converge com o que foi enunciado por Colantonio (2009), que, em seu estudo, percebeu a complementaridade sócio-espacial mais pronunciada de alguns municípios da RMBS com a RMSP, de modo que se chegaria a uma organização urbana "tripartite", onde apena sua porção central assumiria, de fato, uma estrutura metropolitana.

Por fim, a espacialidade dos fluxos migratórios, no Vale do Paraíba e Litoral Norte, igualmente, trabalha por desconstruir, até certo ponto, o padrão centro-periferia, isso porque, tanto São José dos Campos quanto Taubaté, parecem dividir o caráter de pólo metropolitano. Ao lado da RMBS, essa região foi uma das que apresentaram maior 
difusão direcional dos movimentos migratórios, colocando-se em questão o real caráter metropolitano do conjunto de municípios dessas unidades regionais.

\begin{tabular}{|c|c|c|c|}
\hline \multicolumn{4}{|c|}{$\begin{array}{l}\text { Quadro } 1 \text { - Hierarquização dos Centros Urbanos da "Macrometrópole Paulista" a Partir dos } \\
\text { Fluxos Migratórios de 1ª Ordem em 1995-2000 }\end{array}$} \\
\hline Independentes & subordinados - Nível A & subordinados - Nível B & subordinados - Nível C \\
\hline \multirow{26}{*}{ SÃO PAULO } & ATIBAIA & BOM JESUS DOS PERDÖES & \\
\hline & BERTIOGA & & \\
\hline & \multirow{4}{*}{ BRAGANÇA PAULISTA } & JOANÓPOLIS & \\
\hline & & PEDRA BELA & \\
\hline & & PINHALZINHO & TUIUTI \\
\hline & & VARGEM & \\
\hline & COTIA & $\begin{array}{l}\text { VARGEM GRANDE PAULISTA } \\
\end{array}$ & \\
\hline & EMBU-GUAÇU & & \\
\hline & GUARULHOS & NAZARÉ PAULISTA & \\
\hline & ITANHAÉM & & \\
\hline & ITAPECERICA DA SERRA & & \\
\hline & MAIRIPORÃ & & \\
\hline & PERUÍBE & & \\
\hline & PIRACAIA & ANALÂNDIA & \\
\hline & \multirow{6}{*}{ PIRACICABA } & CHARQUEADA & \\
\hline & & IRACEMÁPOLIS & \\
\hline & & RIO DAS PEDRAS & MOMBUCA \\
\hline & & SALTINHO & \\
\hline & & SÃOPFDRO & ÁGUAS DE SÃO PEDRO \\
\hline & & SAOPEDRO & SANTA MARIA DA SERRA \\
\hline & PIRAPORA DO BOM JESUS & & \\
\hline & \multirow{3}{*}{ RIO CLARO } & CORUMBATAÍ & \\
\hline & & IPEÚNA & \\
\hline & & SANTA GERTRUDES & \\
\hline & SÃO SEBASTIÃO & ILHABELA & \\
\hline & TABOÃO DA SERRA & & \\
\hline \multirow{3}{*}{ SÃO BERNARDO DO CAMPO } & DIADEMA & & \\
\hline & & MAUÁ & \\
\hline & SANTO ANDRE & SÃO CAETANO DO SUL & \\
\hline \multirow{3}{*}{ ITAQUAQUECETUBA } & ARUJÁ & $\begin{array}{l}\text { SANTA ISABEL } \\
\end{array}$ & \\
\hline & & POÁ & \\
\hline & SUZANO & RIBEIRÃO PIRES & RIO GRANDE DA SERRA \\
\hline \multirow{3}{*}{ PRAIA GRANDE } & MONGAGUÁ & & \\
\hline & \multirow{2}{*}{ SÃO VICENTE } & CUBATÃO & \\
\hline & & SANTOS & GUARUJÁ \\
\hline \multirow{9}{*}{ CAMPINAS } & HORTOLĀNDIA & SUMARÉ & NOVA ODESSA \\
\hline & INDAIATUBA & & \\
\hline & JAGUARIÚNA & & \\
\hline & LIMEIRA & CORDEIRÓPOLIS & \\
\hline & MONTE MOR & & \\
\hline & PAULÍNIA & & \\
\hline & PEDREIRA & & \\
\hline & SANTO ANTÔNIO DE POSSE & & \\
\hline & VALINHOS & VINHEDO & \\
\hline \multirow{13}{*}{ SOROCABA } & ALUMÍNIO & & \\
\hline & ARAÇOIABA DA SERRA & & \\
\hline & BOITUVA & IPERÓ & \\
\hline & $\begin{array}{l}\text { PIEDADE } \\
\end{array}$ & IBIÚNA & \\
\hline & PORANGABA & & \\
\hline & PORTO FELIZ & & \\
\hline & & CONCHAL & \\
\hline & SALTO DE PIRAPORA & LEME & ARARAS \\
\hline & & CAPELA DO ALTO & \\
\hline & TATUÍ & CESÁRIO LANGE & \\
\hline & & QUADRA & \\
\hline & TORRE DE PEDRA & & \\
\hline & VOTORANTIM & & \\
\hline OSASCO & & & \\
\hline & BANANAL & & \\
\hline & CAÇAPAVA & & \\
\hline & CARAGUATATURA & JAMBEIRO & \\
\hline & CARAGUAIAIUBA & PARAIBUNA & \\
\hline & & AREIAS & \\
\hline & CRUZEIRO & LAVRINHAS & \\
\hline SAO JOSE DOS CAMPOS & & QUELUZ & \\
\hline & & CUNHA & \\
\hline & GUARATINGUETÁ & & CACHOEIRA PAULISTA \\
\hline & GUARATINGUETA & LORENA & CANAS \\
\hline & & & PIQUETE \\
\hline & JACAREÍ & GUARAREMA & \\
\hline
\end{tabular}




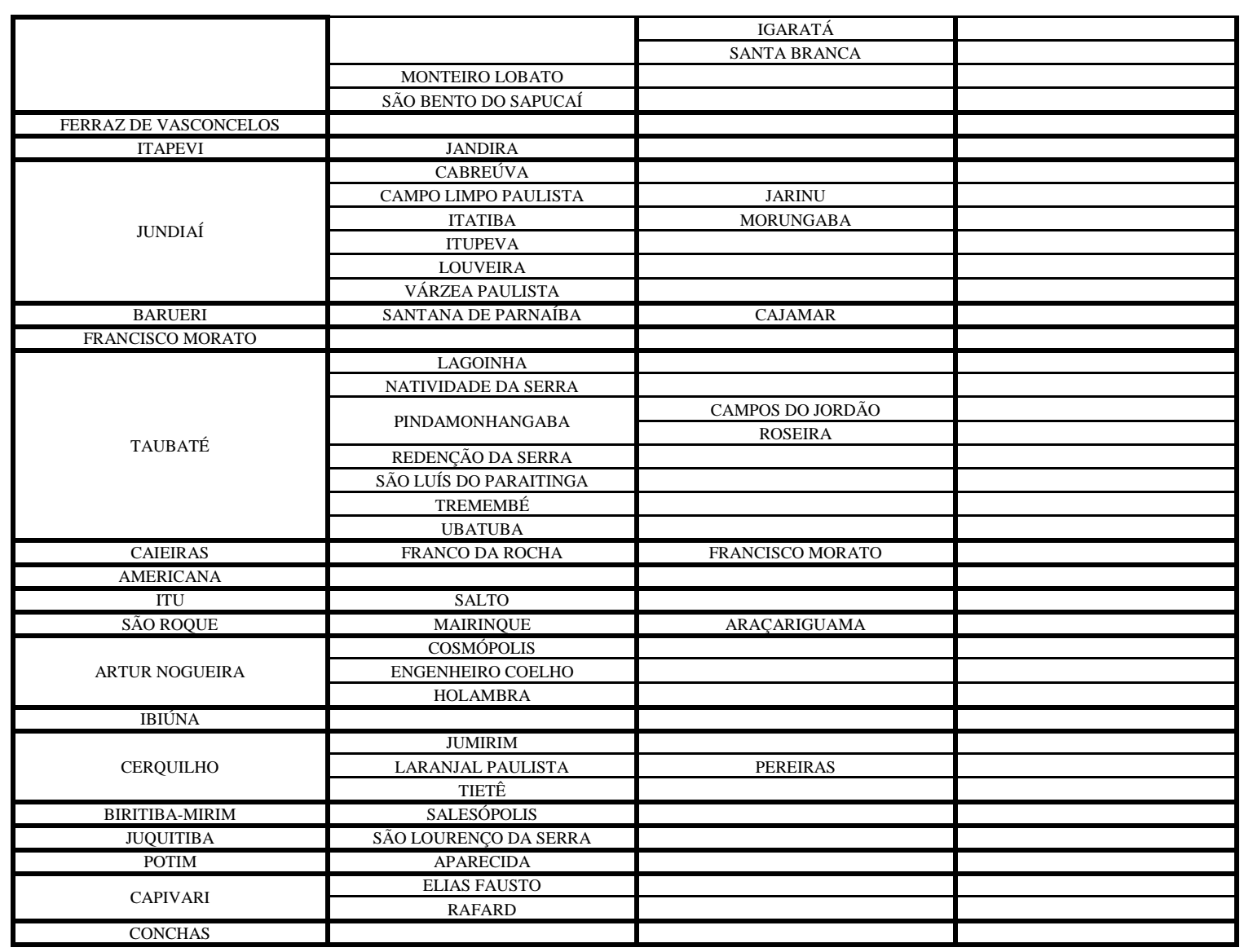

Fonte: IBGE. Dados Brutos do Censo Demográfico 2000.

Organização: Autores

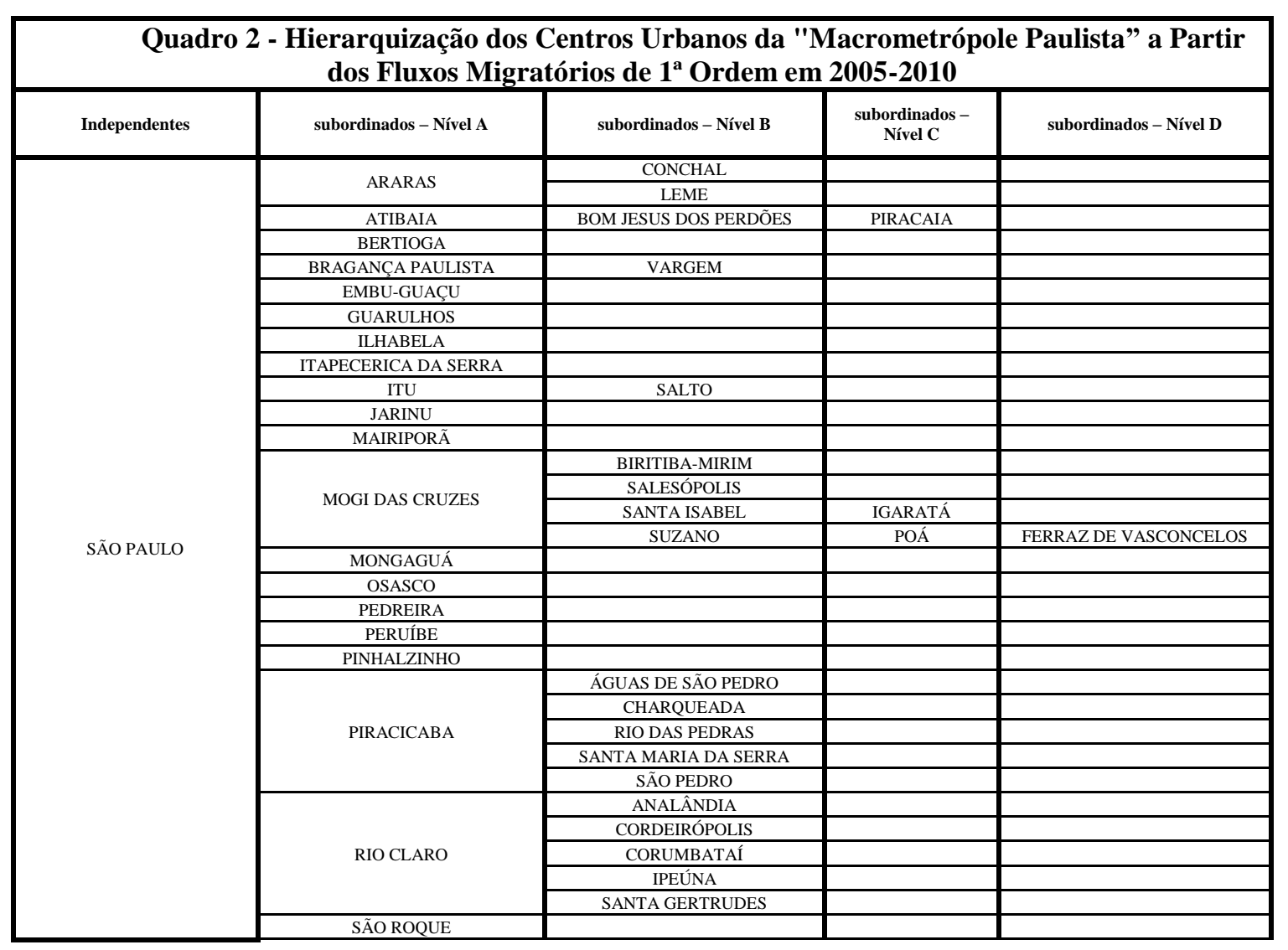




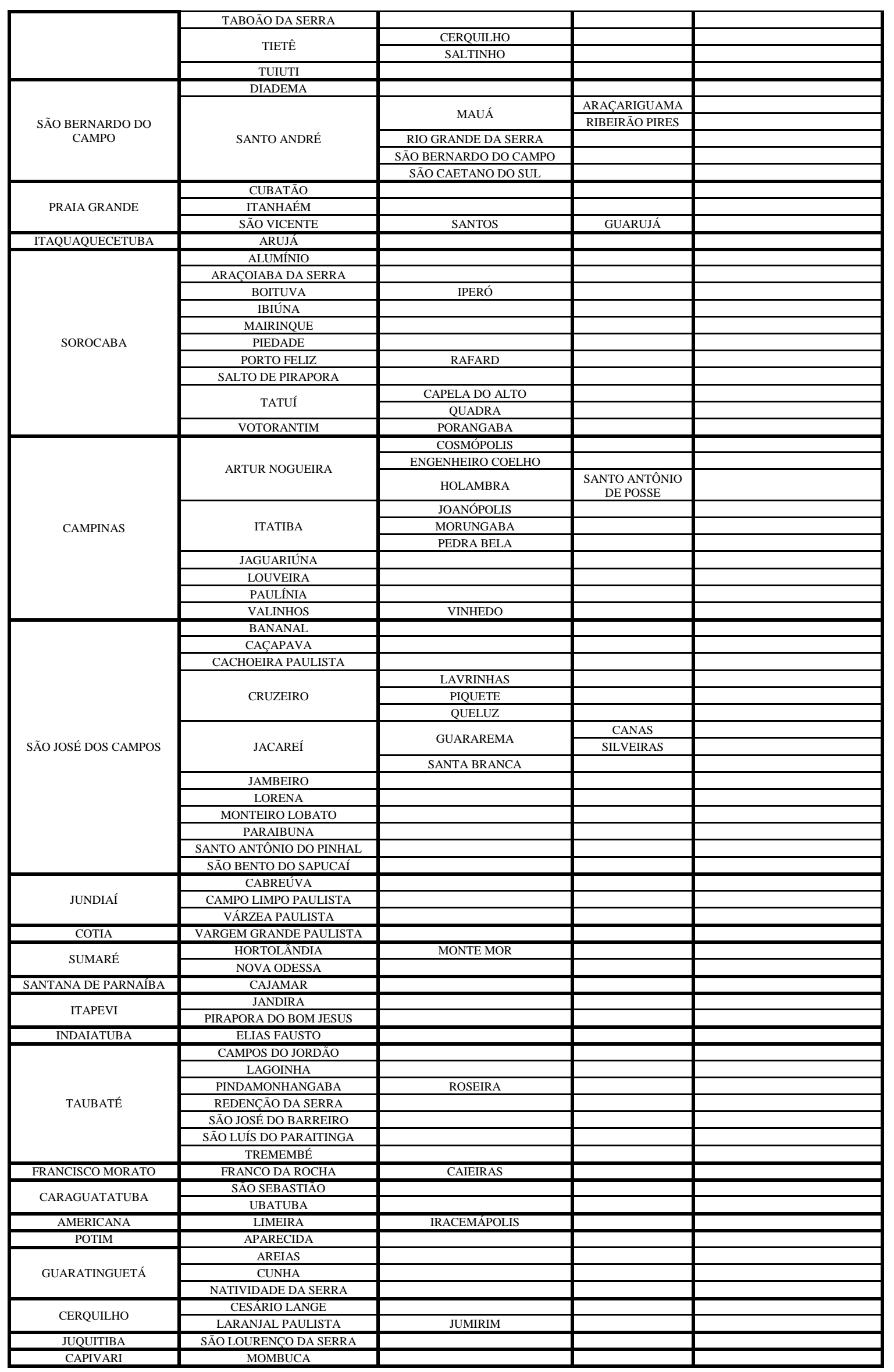

Fonte: IBGE. Dados Brutos do Censo Demográfico 2010.

Organização: Autores 


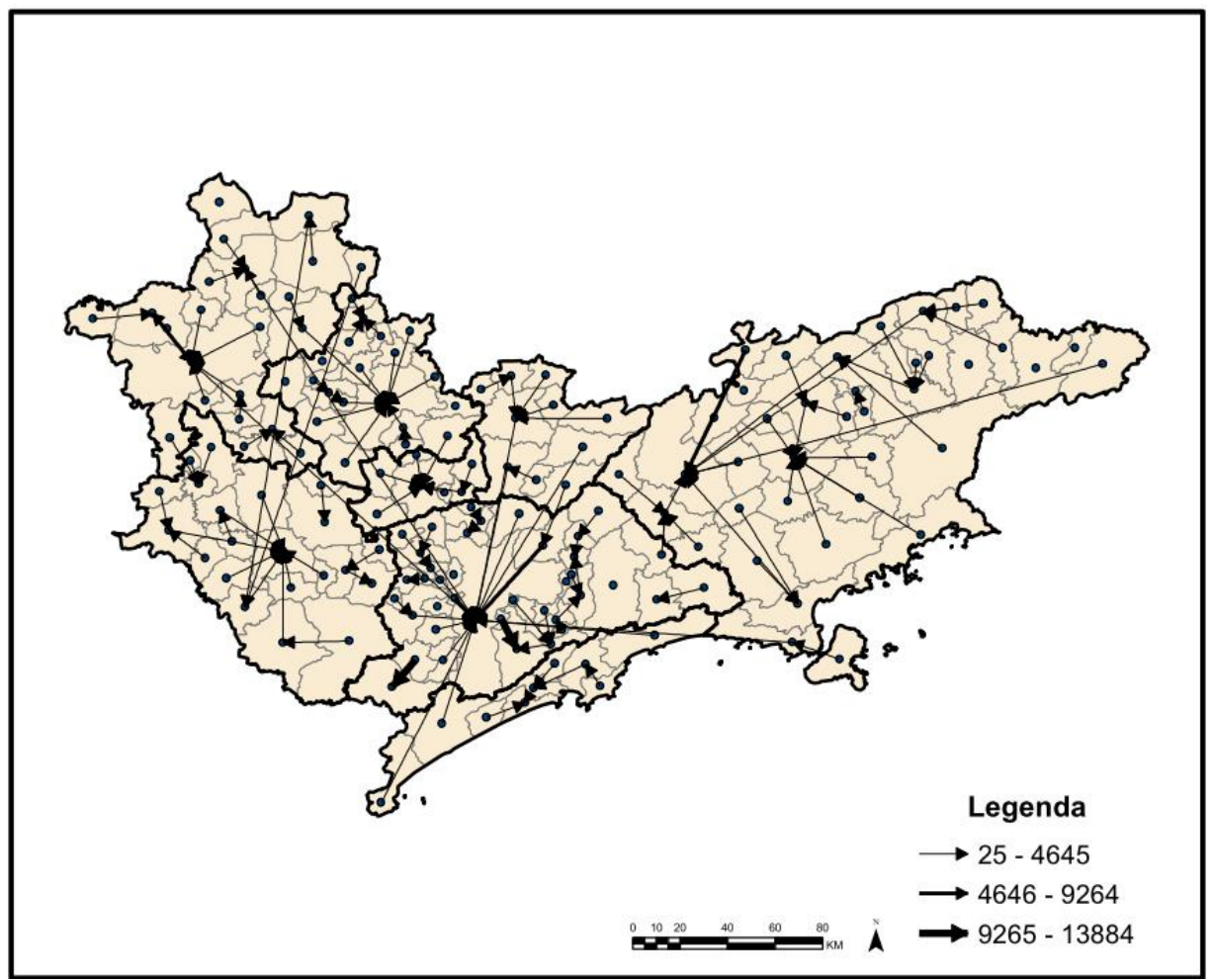

Mapa 2 - Fluxos Migratórios 1995-2000 de Primeira Ordem entre os Centros Urbanos da "Macrometrópole Paulista"

Fonte: IBGE. Dados Brutos do Censo Demográfico 2000. Organização: Autores.

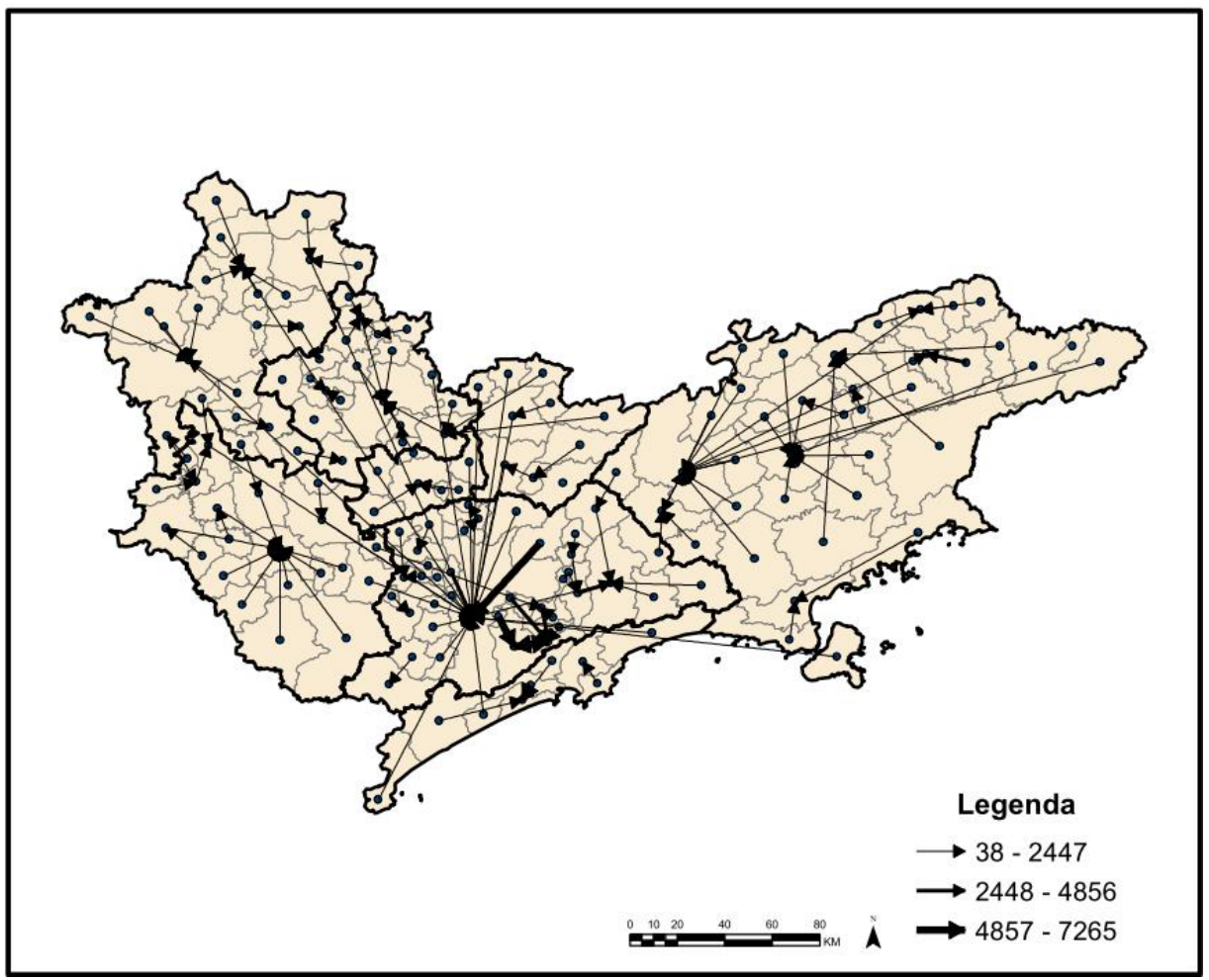

Mapa 3 - Fluxos Migratórios 2005-2010 de Primeira Ordem entre os Centros Urbanos da "Macrometrópole Paulista"

Fonte: IBGE. Dados Brutos do Censo Demográfico 2010. Organização: Autores. 


\section{Considerações Finais}

Com os poucos resultados trazidos até aqui, apresentados mais de forma descritiva do que analítica, pôde-se verificar as potencialidades da aplicação da Teoria dos Grafos ao estudo dos Fluxos Migratórios conjugados ao processo de formação da aglomeração urbano-regional elegida enquanto área de estudo. De fato, observaram-se as potencialidades de avaliação de um fenômeno social que resguarda tanto características de ocorrência na escala da rede urbana (montagem de uma hierarquia urbana entre os municípios considerados) e na escala do espaço urbano (delimitação em linhas gerais das regiões metropolitanas e aglomerações urbanas pela hinterlândia dos centros independentes, como também, a visualização ainda de um padrão centroperiferia no interior das mesmas).

Em suma, os fluxos migratórios de $1^{\mathrm{a}}$ ordem e a hierarquia urbana construída partir dos mesmos, mostraram que a modalidade migratória predominante para tal foi restrita espacialmente ao interior das unidades regionais que conformam a "Macrometrópole Paulista". Além disso, verificou-se uma primazia de metrópole paulistana como destino desses fluxos, sendo, por isso, um dos centros urbanos independentes e que subordinava sozinho o maior número de municípios, de acordo com o modelo de análise seguido pelo trabalho.

Ressalta-se, todavia, que ainda muitas lacunas não foram preenchidas, em virtude do número relativamente limitado de variáveis utilizadas. De fato, pouco da complementaridade sócio-espacial entre as unidades regionais foi captada com os dados utilizados no estudo. Impele-se, porquanto, seguir a análise se utilizando os fluxos migratórios de primeira ordem relacionados com os deslocamentos pendulares, como também, outras variáveis sócio-demográficas, por meio dos quais se poderia entender mais a natureza sócio-espacial do processo de formação da "Macrometrópole Paulista".

\section{Referências bibliográficas}

COLANTONIO, F. C. Região metropolitana da Baixada Santista: transformações recentes. Dissertação (Mestrado em Desenvolvimento Econômico).Universidade Estadual de Campinas. Campinas, 2009.

CORRÊA, R.L.(orgs). Sobre Agentes Sociais, Escala e Produção do Espaço: um texto para discussão. (Texto Inédito), ca. 2011. 
Ensino n $^{\circ} 1,1999$.

Redes Geográficas e Teoria dos Grafos. Textos LAGET. Pesquisa e

Estudos sobre a rede urbana. Rio de Janeiro, Bertrand Brasil, 2006.

CUNHA, J.M.P.. Mobilidade espacial da população: Desafios teóricos $e$ metodológicos para o seu estudo. Campinas: Núcleo de Estudos de PopulaçãoNepo/Unicamp, 2011.

et all. 2013. Movimentos pendulares na MMP. Relatório de pesquisa de apoio à elaboração do Plano de Ação da Macrometrópole Paulista (PAM). NEPOUNICAMP/FUNDAP/EMPLASA. São Paulo.

DAVIDOVICH, F. "A 'volta da metrópole' no Brasil: referências para a gestão territorial. In: RIBEIRO, L. C. de Q. (org.). Metrópoles entre a coesão e a fragmentação, a cooperação e o conflito. São Paulo/Rio de Janeiro, Editora Fundação Perseu Abramo/ FASE - Federação de Órgãos para Assistência Social e Educacional. 2004.

EMPLASA. Macrometrópole Paulista. São Paulo, SP: Empresa Metropolitana de Planejamento da Grande São Paulo. 2012. Disponível em http://www.emplasa.sp.gov.br/emplasa/.*

FARIAS, L.A.C.. Interações Espaciais na Rede Urbana Fluminense: Uma Análise Comparativa dos Deslocamentos Pendulares de População em 2000 e 2010. (Dissertação de Mestrado). Rio de Janeiro. UFRJ/PPGG.2014.

GARRISON, W. L. Connectivity of the Interstate Highway Sytem. Spatial analysis - A Reader in Statistical Geography. Ed. B. J. L. Berry and D. F. Marble. Prentice Hall Inc., Englewood cliffs (1968), pp. 239-249.

GOEI, B; BURGER, M.J.; OORT, F.G. van; KITSON, M. Functional Polycentrism and Urban Network Development in the Greater South East UK: Evidence from Commuting Patterns, 1981-2001. Report Series Research in Management. ERS-2009-038-ORS. 2009.

HARARY, F. Graph Theory- Series in Mathematics. Addison Wesley Publishing Co., Reading. Massachussetts, 1969.

JAKOB, A. A. E..Análise sócio-demográfica da constituição do espaço urbano da Região Metropolitana da Baixada Santista no período 1960-2000. Campinas, 2003. 220f. Tese (Doutorado em Demografia) - Instituto de Filosofia e Ciências Humanas, Universidade Estadual de Campinas.

MOURA, R. 2009. Arranjos urbano-regionais no Brasil: uma análise com foco em Curitiba. Tese (Doutorado em Geografia), Universidade Federal do Paraná, Curitiba.

NYSTUEN, J. e DACEY, M.. A Graph Theory Interpretation of Nodal Regions. Papers and Proceedings of the Regional Science Association, 7. 1961. 
RAMOS, T. M. de A.. Interações espaciais no Estado de São Paulo: uma análise comparativa entre dois tipos de redes. Dissertação (Mestrado em Geografia). Departamento de Geografia, Universidade Federal do Rio de Janeiro, 1998.

TEIXEIRA, M. V. P. C.. Padrões de Ligações e Sistema Urbano: Uma Análise Aplicada aos Estados da Guanabara e Rio de Janeiro. Revista Brasileira de Geografia, 37 (3). 1975.

VAN OORT, F.G., BURGER, M.J., RASPE, O. On the economic foundation of the urban network paradigm. Spatial integration, functional integration and economic complementarities within the Dutch Randstad. Urban Studies (forthcoming). 2009. 